\title{
V2G enabled EVs providing frequency containment reserves: field results
}

\author{
Banol Arias, Nataly; Hashemi, Seyedmostafa; Andersen, Peter Bach; Traholt, Chresten; Romero, Ruben
}

Published in:

Proceedings of 2018 IEEE International Conference on Industrial Technology

Link to article, DOI:

10.1109/ICIT.2018.8352459

Publication date:

2018

Document Version

Peer reviewed version

Link back to DTU Orbit

Citation (APA):

Banol Arias, N., Hashemi, S., Andersen, P. B., Traholt, C., \& Romero, R. (2018). V2G enabled EVs providing frequency containment reserves: field results. In Proceedings of 2018 IEEE International Conference on Industrial Technology (pp. 1814-19). IEEE. https://doi.org/10.1109/ICIT.2018.8352459

\section{General rights}

Copyright and moral rights for the publications made accessible in the public portal are retained by the authors and/or other copyright owners and it is a condition of accessing publications that users recognise and abide by the legal requirements associated with these rights.

- Users may download and print one copy of any publication from the public portal for the purpose of private study or research.

- You may not further distribute the material or use it for any profit-making activity or commercial gain

- You may freely distribute the URL identifying the publication in the public portal 


\section{V2G Enabled EVs Providing Frequency Containment Reserves: Field Results}

\author{
Nataly Bañol Arias \\ Electrical Engineering Department \\ UNESP - Sao Paulo State University \\ Ilha Solteira, São Paulo, Brasil \\ natycanta@aluno.feis.unesp.br
}

\author{
Seyedmostafa Hashemi, Peter Bach \\ Andersen, Chresten Træholt \\ Center for Electric Power and Energy \\ Technical University of Denmark \\ Kongens, Lygnby, Denmark \\ $\{$ shtog, pba, ctr\}@elektro.dtu.dk
}

\author{
Rubén Romero \\ Electrical Engineering Department \\ UNESP - Sao Paulo State University \\ Ilha Solteira, São Paulo, Brasil \\ ruben@dee.feis.unesp.br
}

\begin{abstract}
Frequency regulation is procured by transmission system operators (TSOs) to ensure stable and reliable operation of power systems. In the Nordic energy region, frequencycontrolled normal operation reserve (FNR) is one of the services that require fast-response. Electric vehicles (EVs) with vehicle to grid (V2G) capability may be considered an FNR provider in a future renewable-based power system. This paper presents results from the first commercial V2G hub in the Nordic area using the EV fleet of Frederiksberg Forsyning. The results are achieved by participating in the Danish frequency regulation market, and provide an analysis of the EV fleet operational data. Additionally, an analysis on practical issues that may result from realistic implementation of frequency regulation, such as delays, measurement errors and physical equipment constraints is given. These issues must be taken into account when developing new strategies for providing frequency services with EVs in a future scenario. Results show that a set of EVs operating in aggregated mode is able to support the grid while satisfying the primary goal of the $\mathrm{EV}$ fleet, i.e. transportation of fleet customers.
\end{abstract}

Keywords-Electric vehicles, EV fleet, Frequency regulation, Services, Practical issues.

\section{INTRODUCTION}

The stability and reliability of power systems can be jeopardized by increasing penetration of distributed energy resources due to the intermittent nature of their output power [1]. Transmission system operators (TSOs), who are responsible for the grid stability and security, maintain the balance between the electricity consumption and production by procuring ancillary services such as frequency and voltage regulation. Frequency regulation is one of the most common services procured by TSOs to ensure stable and reliable operation of power systems. The service can be provided by generation and/or by demand. A prominent and new option are pooled EVs due to the manageable nature of their loads, availability, bidirectional power capacity and quick response time [2]. Considering the entrance barrier in terms of power EVs should operate in an aggregated mode in order to ensure a sufficient capacity for participating in the frequency markets.

Realistic implementations of frequency regulation using EV fleets in the North American market have been presented in
[3]-[5]. In [3], the authors present an overview of a vehicle-togrid (V2G) demonstration project, in which a real EV fleet provides frequency regulation in the California Independent System Operator (CAISO) market. A centralized method based on a mixed-integer linear programming model is developed to optimize the EV charging and the bid capacity while minimizing the operation cost and maximizing the profit of the aggregator for providing frequency regulation. In [4], a comparison between a centralized and decentralized method in terms of the bid capacity and the computational scalability is carried out based on simulations while in [5], the authors describe an implemented and deployed multi-agent system. In [6] a model is proposed to forecast the availability of an EV fleet for providing frequency regulation in the PJM market. The model is developed based on parameters such as route locations and the state of charge of the EVs. Comparing with [4] and [5], the work in [6] does not address a realistic implementation of frequency regulation using an EV fleet.

In European countries, frequency regulation using EV fleets have been studied in [7] and [8]. The authors in [7] develop an economic evaluation for an EV fleet participating in the French frequency regulation market, exploring regulation strategies for both unidirectional and bidirectional (V2G) power exchanges. Meanwhile, in [8] an analysis of frequency regulation services via V2G within a micro-grid environment is carried out in Macedonia. The results of the aforementioned works are based on simulations. Moreover, an analysis in [9] is focused on user behavior and EV energy consumption of a real EV fleet operation. Although a large amount of useful data regarding trips and state of charge of the EVs is provided in this work, the implementation of frequency regulation is not considered within the analysis.

In this paper, we focus on a real demonstration of frequency-controlled normal operation reserve (FNR) in Denmark provided by an EV fleet through the Parker project. This is the first project carrying out a demonstration of the participation of an EV fleet in the Nordic area. For this demonstration Nissan EVs, electric vehicle supply equipment's (EVSEs), commonly known as chargers and an aggregation software were used. Thus, the EVs provide regulation power to the grid through the EVSEs, which, at the same time are 
equipped with telecommunication between the EVs and the aggregator. The aggregator is responsible for bidding into the market and facilitates the communication between the EV owners and the TSO. It also controls the charging or discharging power of each EV using the aggregation software. This paper covers: 1) An assessment of the operation of an EV fleet that participates in the Danish frequency regulation market, which demonstrates that EVs are able to support the grid; 2) analysis of the practical issues that may result from the provision of frequency regulation using EV fleets in realistic environment.

The remaining part of this paper is organized as follows. In Section II, the Danish frequency regulation market along with the regulation services using an EV fleet are described. Section III presents and analyzes the EV fleet operation providing FNR based on one-week real data. Finally, the conclusions and the future work are presented in Section IV.

\section{FREQUENCY NORMAL OPERATION RESERVE PROVISION BY FREDERIKSBERG FORSYNING EV FLEET}

\section{A. Danish Frequency Regulation Market}

Europe is split into five synchronous areas defined by the European Network of Transmission System Operators (ENTSO-E) with a nominal frequency of $50 \mathrm{~Hz}$, without being synchronized with each other. Denmark is split into two synchronous areas: Jutland and Funen belong to Regional Group (RG) continental Europe and Zealand belongs to RG Nordic. These areas are termed Western Denmark or DK1 and Eastern Denmark or DK2, respectively. Available frequency reserves in DK1 and DK2 are presented in Table I [10]. Frequency-controlled reserves are procured to ensure balance between consumption and generation in real-time. The aim is to automatically stabilize the frequency at $50 \mathrm{~Hz}$ and minimize frequency deviations. The EV fleet subjected to this analysis is providing Frequency-controlled normal operation reserve (FNR) services to Energinet, which is the TSO in Denmark.

FNR is an automatic response provided by production or consumption units. It is a bidirectional frequency control activated for both under and over frequencies. According to the Danish market rules regarding FNR only symmetrical bids are allowed, which means that up and down regulations reserves should be offered together [10]. In the Danish frequency regulation market, the TSOs in the Nordic Synchronous area are responsible for the supply of FNR reserves. The combined requirement in the ENTSO-E RG Nordic is $600 \mathrm{MW}$ and each TSO contributes separately to the total requirement. In this case, Energinet is responsible for the supply based on the production in Eastern Denmark. When the frequency deviation is up to $+/-100 \mathrm{mHz}$ compared with the reference $(50 \mathrm{~Hz})$, FNR must be activated according to the linear function depicted in Fig. 1. The service must be fully activated within 150 seconds while continuously supplying power.

FNR is procured one or two days ahead of the day of operation. The suppliers can submit hourly bids, or in time blocks, under special conditions. All bids must be submitted via the self-service portal of Energinet. Bids submitted to the auction two days before must be submitted no later than
TABLE I. RESERVE AVAILABLE IN DK1 \& DK2

\begin{tabular}{c|c|c}
\hline & DK1 & DK2 \\
\hline \multirow{4}{*}{ Service } & $\begin{array}{c}\text { Primary frequency reserve } \\
\text { (PFR) }\end{array}$ & $\begin{array}{r}\text { Frequency-controlled disturbance } \\
\text { reserve (FDR) }\end{array}$ \\
\cline { 2 - 3 } & Secondary reserve, aFRR & $\begin{array}{r}\text { Frequency-controlled normal operation } \\
\text { reserve (FNR) }\end{array}$ \\
\cline { 2 - 3 } & Manual reserves, mFRR & Secondary reserve, aFRR \\
\cline { 2 - 3 } & & Manual reserves, mFRR \\
\hline
\end{tabular}

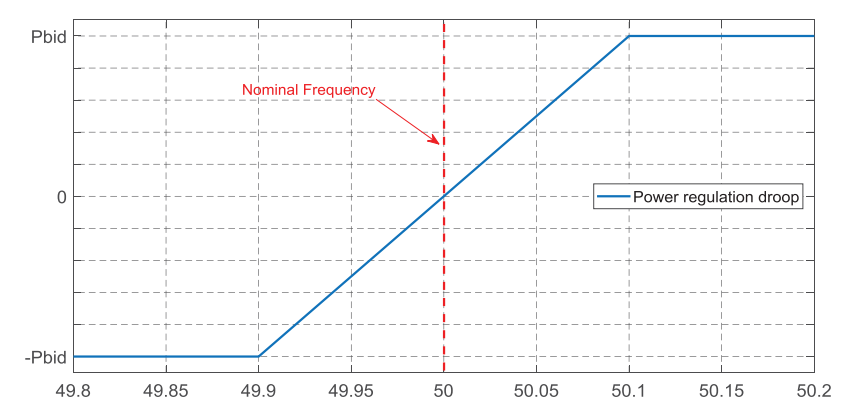

Fig. 1. Droop control for FNR service.

15:00h, and those submitted to the auction one day before must be submitted no later than 18:00h the day before. The volume and the hour-by-hour price must be defined in the bidding process in MWs and DKK/MW or EUR/MW, respectively. Moreover, the minimum bid must be $0.3 \mathrm{MW}$. All bids are sorted and accepted according to price, until the total requirement is covered. The service is compensated based on an availability payment and pay-as-bid, and in case of activation, it is compensated using the regulating power prices for upward and downward regulation. Moreover, the players should be able to provide any documentation from the SCADA system in case that Energinet decides to check the service. The checking process is carried out by sampling or, when notable frequency deviations are observed.

To participate in the frequency market EVs act as production or consumption units. It means that they would charge and/or discharge their batteries depending on the frequency signal using the battery as a storage device. Thus, when upward regulation is required the EVSE should discharge the battery, while in downward regulation the EVSE should charge the battery, as shown in Fig. 2.

\section{B. Frederiksberg Forsyning EV Fleet composition}

The EV fleet of Frederiksberg Forsyning is providing FNR services to Energinet, the Danish TSO, through the aggregator. The EV fleet is part of a public utility company (Frederiksberg Forsyning) which is dedicated to provide maintenance services related to domestic gas, tap water, district heating and sewage in the greater Copenhagen. The EV fleet is composed of 10 Nissan eNV200 electric vans with battery capacity each of 24 $\mathrm{kWh}$. There are 10 ENEL V2G chargers with maximum and minimum power rating of $+/-10 \mathrm{~kW}$, allowing for simultaneous charging of all EVs. Fig. 3 depicts some of the cars and chargers in the utility company [11]. 


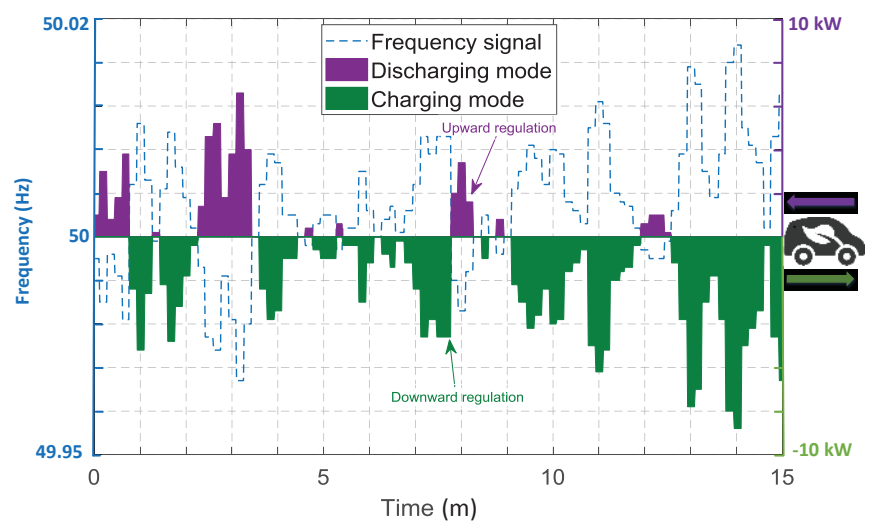

Fig. 2. FNR service provided by EVs..

\section{Aggregator}

The role of the aggregator, as the name suggests, is aggregating a group of EVs and presenting them as a single unit to the system operator, facilitating the communication between the EV owners and the TSO [5]. The aggregator has the responsibility of bidding into the market as well as accomplishes the bid commitments. After the submission and acceptance of the bids, the aggregator must schedule the EV fleet operation following the frequency signal. The EVs should be scheduled hour-by-hour according to the regulation power decided in the bid process. The frequency signal is measured with one-second resolution and it should be followed by the EVs considering a preferred operating point (POP) [5]. The POP is a mechanism used to ensure a suitable EV's state of charge (SOC) to be able to provide regulation services at any time. Thus, the POP mechanism avoids the EV to be fully charged or fully discharged along the regulation period.

\section{Communication process between the parties}

A communication structure between the chargers, the EVs, the aggregator and the TSO is required. During the regulation period, the TSO sends signals to the aggregator, requesting the contracted frequency services. The aggregator must supply the requirements by controlling the charging or discharging power of each EV at any time. Therefore, the aggregator calculates the total power required based on the frequency signal, and afterward, divides it between all the EVs available for providing services at that specific time, according to an internal algorithm. This procedure determines the control actions for each EV. For this purpose, the chargers are equipped with devices that allow the communication between the EVs and the aggregator. These devices have implemented a mechanism called "Grid Integrated Vehicle (GIV)" which comprises a set of algorithms properly developed by the aggregator [4], used to control the power of the EVs.

\section{ANALYSIS OF THE FIELD RESULTS}

The analysis of the EV fleet operation has been carried out based on data from one complete week, from Friday $9^{\text {th }}$ to Saturday $17^{\text {th }}$ of September 2017 with one-second resolution. The data contains information related to the SOC of the EVs, power bid, power requested, and power provided. A detailed

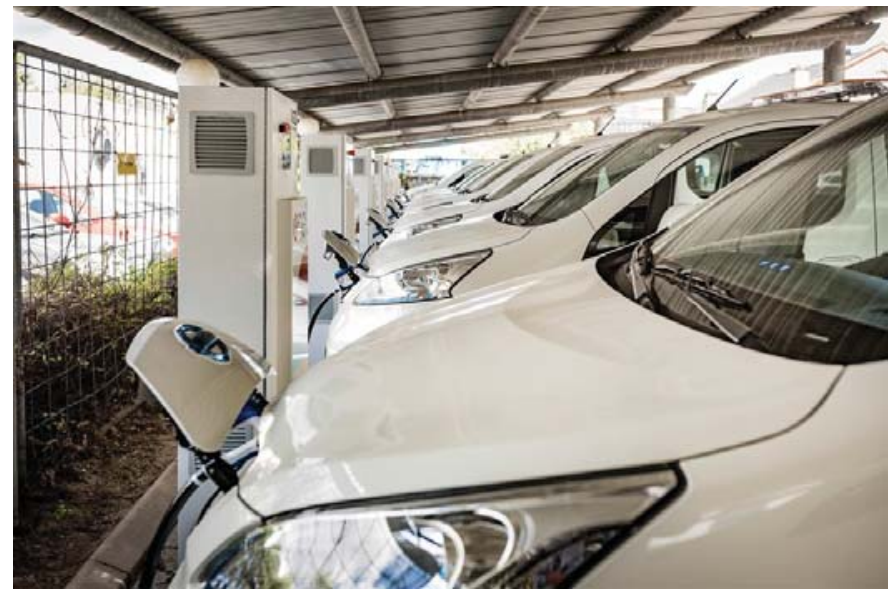

Fig. 3. EV fleet in the headquarter of Frederiksberg Forsyning [11].

analysis of these parameters will be presented in this Section. For simplicity and better comprehension, some of the analysis will carried out using shorter periods, for instance, one day, one hour, or minutes.

\section{A. General Considerations}

- The frequency regulation period considered for the analysis starts from 16:00h to 06:00h of the next day.

- The capacity of the EV batteries is $24 \mathrm{kWh}$. However, considering the customer preference and the battery life span, the working capacity for FNR is decreased.

- The power rated of each charger is $10 \mathrm{~kW}$. However, the maximum and minimum power rated used for providing FNR is $+/-9.25 \mathrm{~kW}$.

\section{B. Analysis for one individual car during the complete week}

1) SOC behaviour: Fig. 4a. shows the SOC of one specific car during the complete week. As can be seen, the SOC of the EV between September $10^{\text {th }}$ and $11^{\text {th }}$ does not have any interruption because this period corresponds to one weekend day, in which the car is available to provide service at any time. On the contrary, during the other days, there are interruption periods corresponding to the workday where the car is out driving. Additionally, note from Fig. 4a. that the initial SOC of the $\mathrm{EV}$ is different at the beginning of each regulation period. It is because the initial SOC of the EV highly depends on the user behavior. In this EV fleet, the EVs are used mainly for maintenance and service tasks. Then, the initial SOC depends on the kilometers driven during the work time, i.e., between $08: 00 \mathrm{~h}$ and $16: 00 \mathrm{~h}$. Similarly, the final $\mathrm{SOC}$ at the end of the regulation period $(06: 00 \mathrm{~h})$ is different each day. This value depends on the exchanged energy during the regulation period. It is important to mention that the EV should be fully charge before the starting time of the workday. In this way, the period between $06: 00 \mathrm{~h}$ and $07: 59 \mathrm{~h}$ is used to bring the SOC of the EV to a suitable level before the departure time. The daily SOC behaviour provides useful information for the aggregator, since it defines the daily available energy from each car to provide regulation services. Based on this information, the aggregator can calculate the 

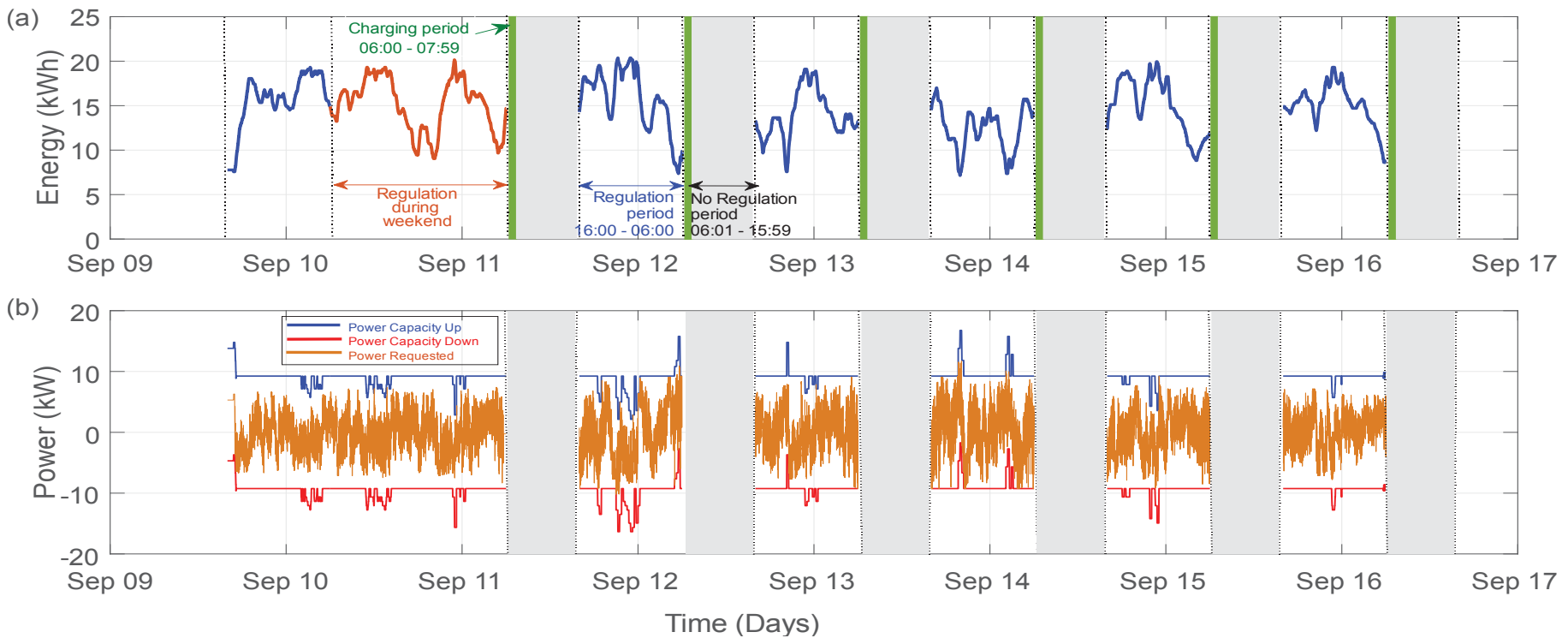

Fig. 4. Analysis of one car during the complete week. a) SOC behaviour. b) Power bid capacity and power requested.

daily estimated bid capacity of each EV in order to optimize its participation in the market.

2) Availability of the car: The fact that the EV is not always available to provide services can be seen in Fig. 4a. Note that during the weekend the EV is only used to provide regulation services, i.e. it is parked (and plugged-in) the whole day. In contrast, during weekdays there is a period in which the EV does not provide services. It corresponds to the work hours (between 08:00h and 16:00h), in which the EV is used for customer services. Since the departure and the arrival time of each EV highly depend on the user behaviour, further statistical analysis focused on weekdays can be carried out, in order to increase the availability of the cars for services provision during this period, and in an attempt to improve the aggregator profit.

3) Up and down regulation: Fig.4b. shows that the power bid capacity for regulation up and regulation down is always symmetric, which is one of the requirements for providing FNR in the Danish market regulation. It can be seen that the power requested is always mantained between the limits of the power bid capacity.

\section{Analysis of one individual car during one day.}

For this case, data from the regulation period during one weekday (between Tuesday $12^{\text {th }}$ and Wednesday $13^{\text {th }}$ of September 2017) is considered.

1) Power requested, power provided and SOC: From Fig.5 it is possible to observe that the power requested and the power provided follow the same pattern, mantaining within the allowed limits of the charger, (i.e., around $+/-10 \mathrm{~kW}$ ). A similar behavior can be observed for the EV SOC, which is mantained between the maximum and minimum energy limits previously defined. Furthermore, Fig. 5 shows that the SOC of the EV changes according to the power provided during the regulation period, as expected.
2) Difference between power requested and power provided: Fig. 5 shows that the power requested and power provided follow the same pattern. However, there are some small differences between them. Fig. 6 shows these parameters in detail, based on one second resolution data and for five minutes. It can be seen that the provided power curve slightly differs with the requested power curve in terms of response time and power. These differences may be as a result of delays in EVSE response, physical and technical constraints of the equipment, such as the current steps of the charger, or even by measument errors. It can be seen from Fig. 6 that the time delay is less than 10 seconds, meaning that a very fast response is provided compared to the FNR regulation requirements. These practical limitations should be considered whitin strategies developed to provide frequency regulation, in an attemp to avoid fines implied by failur to provide contracted service, and to improve the aggregator profit.

3) Total energy exchanged: Fig. 7 shows the total energy exchanged (charged and discharged) hour by hour. As can be seen, the amount of energy charged or discharged differs hour by hour. It highly depends on the frequency signal and less so on the SOC of the EV. Additionally, it can be seen that during some hours, e.g. $18: 00 \mathrm{~h}$ and $21: 00 \mathrm{~h}$, the battery is only charged while in 16:00h and 02:00h is only discharged. This information is useful because the revenues are calculated partly based on the energy exchanged. Moreover, since the energy exchanced is directly related to the deph of discharge of the battery, this information can be used when developing strategies to estimate and optimize the life span of the battery.

\section{Analysis of the EV fleet during weekend and weekdays.}

For this case, measurements from the regulation period during one weekend day (between Friday $09^{\text {th }}$ and Saturday $10^{\text {th }}$ of September 2017) and for one weekday (between Tuesday $12^{\text {th }}$ and Wednesday $13^{\text {th }}$ of September 2017) are considered. 


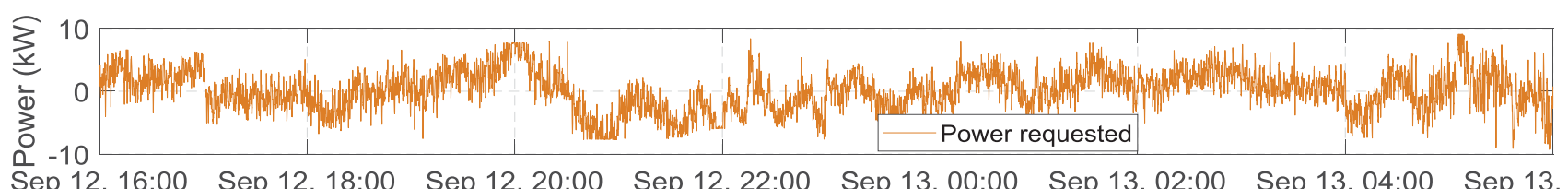

Sep 12, 16:00 Sep 12, 18:00 Sep 12, 20:00 Sep 12, 22:00 Sep 13, 00:00 Sep 13, 02:00 Sep 13, 04:00 Sep 13, 06:00

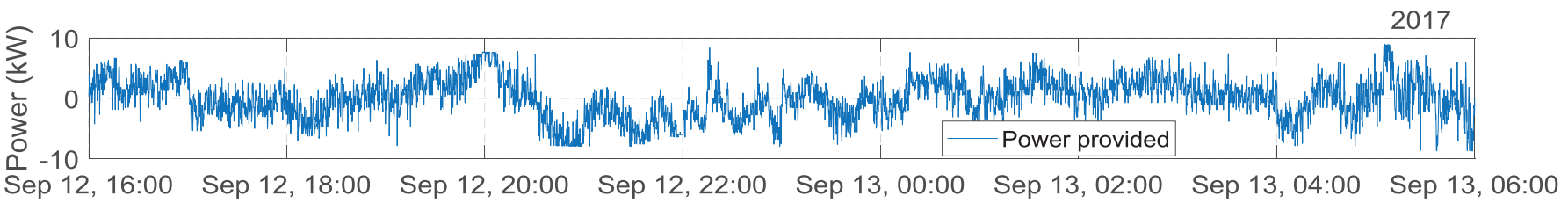

Sep 12, 16:00 Sep 12, 18:00 Sep 12, 20:00 Sep 12, 22:00 Sep 13, 00:00 Sep 13, 02:00 Sep 13, 04:00

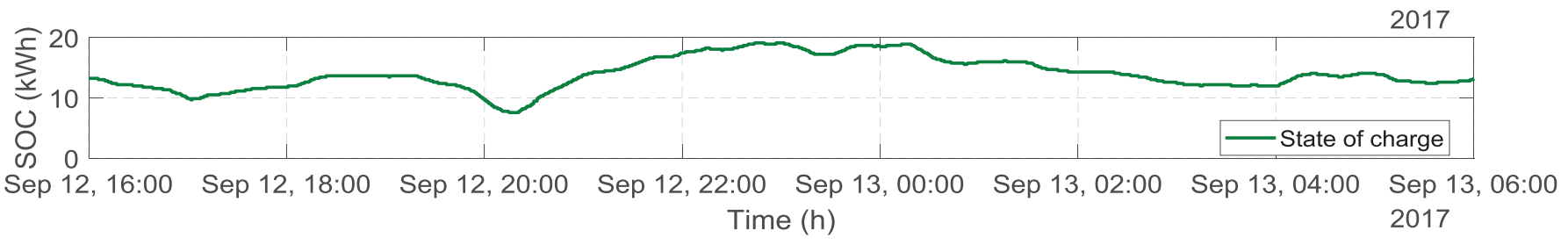

Fig. 5. Power requested, power provided and SOC for one car.

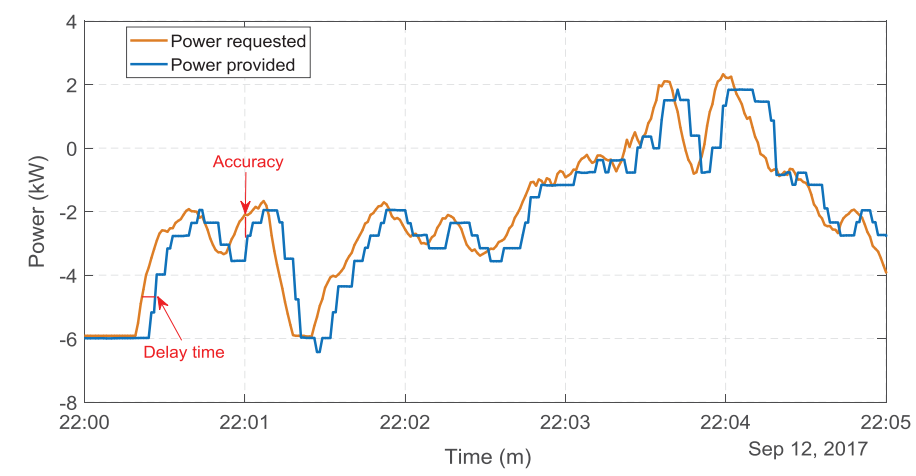

Fig. 6. Difference between power requested and power provided for one car.

1) SOC behaviour: Fig. 8 depicts the SOC for all EVs. As can be seen the initial SOC for all cars and the SOC behavior along the entire regulation period are different for both days. However, the SOC of all EVs follows a similar behavior and at the end of the regulation period, it converges to a similar value. It occurs because the EVs should be prepared for transportation at the starting time of the workday. Moreover, the SOC behavior during the regulation period is similar because all the cars follow the same frequency signal, which defines the power required for each EV. However, it is not exactly the same because the SOC of each EV at the arrival time depends on the user behavior.

2) Charging-discharging limits: To ensure a higher life span of EV batteries and customer preference, maximum and minimum energy capacity limits should be maintained. Note in Fig. 8 that the SOC of all EVs is between 5 and $21 \mathrm{kWh}$.

3) Availability of the cars: As previously mentioned, during the weekend, the cars are used only to provide FNR, which gives the aggregator a higher chance of having all cars

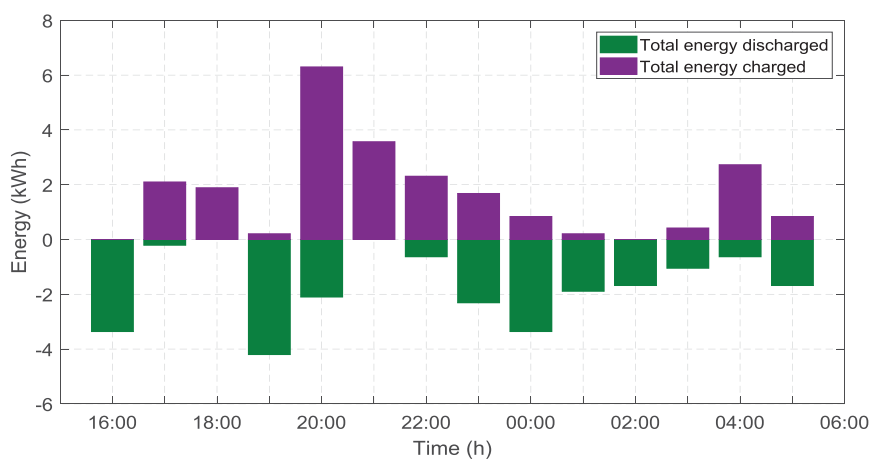

Fig. 7. Hourly energy exchanged for one car.

available for service provision. However, during weekdays many contingencies may occur decreasing the availability of the EVs. Note in Fig. 8 that the SOC of one EV during the weekday is equal to zero, which means that the car is not available to provide regulation services. This fact may affect the operation of other EVs in an attemt to maintain the services provision. Then, this kind of contingencies could be taken into account during the optimization of the bidding process in order to maximize the aggregator profit.

4) Power requested: Fig. 9 shows that the power requested for all EVs is the same most of the time, although there are some periods in which it slightly differs for certain cars. Note from Fig. 9 that at the beginning of the regulation period (16:00), some cars have different power requested. As time goes by, the power requested for all EVs converges to a same value until a decoupling occurs. After this event, a stabilization period is requiered untill all EVs reach the same power required again. The power requested and the POP of all EVs are depicted in Fig.10. 

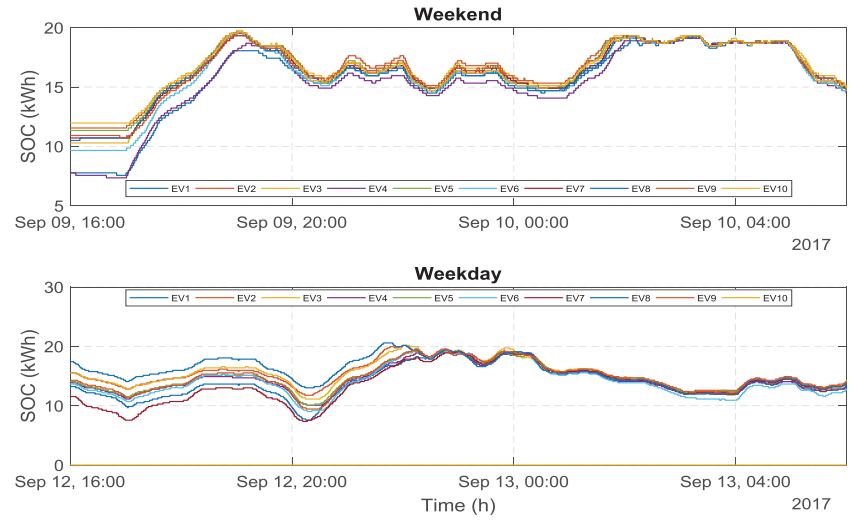

Fig. 8. SOC for each car of the EV fleet.
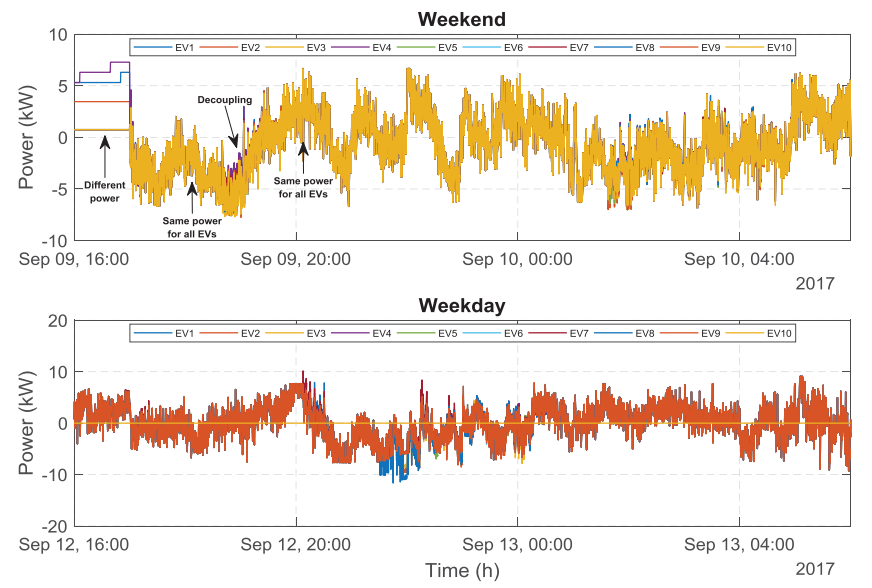

Fig. 9. Power requested for each car of the EV fleet.

\section{CONCLUSION AND FUTURE WORK}

Field results from the EV fleet of Frederiksberg Forsyning, the first commercial V2G hub in the Nordic area providing FNR services were highlighted and analyzed in this paper. Results showed that a pool of EVs operating in aggregated mode are able to in a comprehensive manner support the grid with fast frequency regulation, such as FNR. It was also observed that the availability of the EVs plays an important role in the bidding process, especially during weekdays. Further analysis of the individual EV patterns could be carried out in order to increase the aggregated among of power used to participate in the market. Further analysis of the EV fleet operation during working hours could also be addressed.

Additionally, practical issues, such as communication delays, measurement errors and physical equipment constraints that result from real implementations of FNR, were identified. Considering these limitations within the bidding strategies could substantially improve the efficiency of the regulation service as well as the revenues of the aggregator. As future work, an optimized bidding strategy will be proposed, taking into account the availability of EVs during working hours, aiming at improving the aggregator profit.
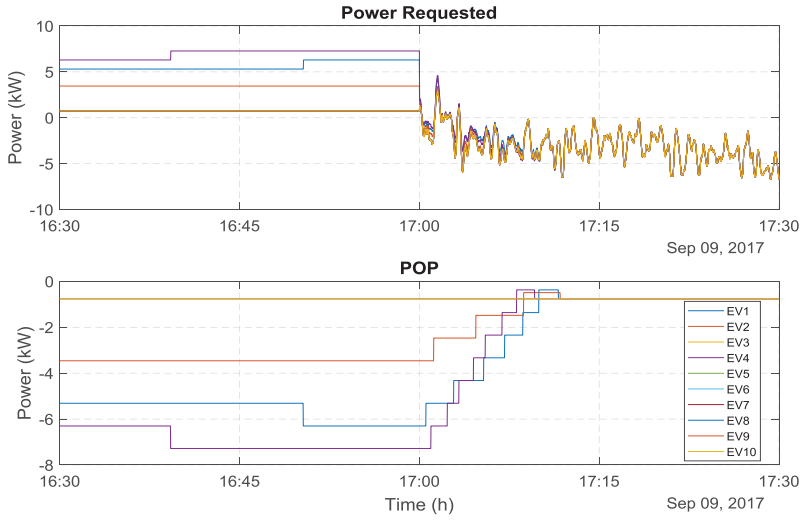

Fig. 10. Power requested for each car of the EV fleet.

\section{ACKNOWLEDGMENT}

The authors would like to thank NUVVE for the provision of data used in this research. This work is supported by the Danish research Parker project under ForskEL contract no. 2016-1-12410, http://parker-project.com.

Nataly Bañol Arias is supported by the Brazilian institution CAPES: PSDE (Programa de Doutorado Sanduíche no Exterior), process nr. 88881.135226/2016-01.

\section{REFERENCES}

[1] R. Bayindir, S. Demirbas, E. Irmak, U. Cetinkaya, A. Ova, and M. Yesil, "Effects of renewable energy sources on the power system," in 2016 IEEE International Power Electronics and Motion Control Conference (PEMC), 2016, pp. 388-393.

[2] E. Romero-Cadaval, F. Barrero-González, E. González-Romera, and M.I. Milanés-Montero, "Using plug-in electric vehicles to implement ancillary services in smart distribution grids," in Plug In Electric Vehicles in Smart Grids: Integration Techniques, S. Rajakaruna, F. Shahnia, and A. Ghosh, Eds. Singapore: Springer Singapore, 2015, pp. 309-349.

[3] N. DeForest, J. S. MacDonald, and D. R. Black, "Day ahead optimization of an electric vehicle fleet providing ancillary services in the Los Angeles Air Force Base vehicle-to-grid demonstration," Appl. Energy, 2017.

[4] S. Vandael, T. Holvoet, G. Deconinck, S. Kamboj, and W. Kempton, "A comparison of two V2G mechanisms for providing ancillary services at the University of Delaware," 2013 IEEE Int. Conf. Smart Grid Commun., no. October, pp. 211-216, 2013.

[5] S. Kamboj, W. Kempton, and K. S. Decker, "Deploying Power GridIntegrated Electric Vehicles as a Multi-Agent System," Inf. Sci. (Ny)., no. Aamas, pp. 13-20, 2011.

[6] J. D. Fitzsimmons et al., "Simulation of an electric vehicle fleet to forecast availability of grid balancing resources," 2016 IEEE Syst. Inf. Eng. Des. Symp. SIEDS 2016, pp. 205-210, 2016.

[7] P. Codani, M. Petit, and Y. Perez, "Participation of an electric vehicle fleet to primary frequency control in France To cite this version: frequency control in France," Int. J. Electr. Hybrid Veh., vol. 7, no. 3, pp. 233-249, 2015.

[8] S. Cundeva and A. Dimovski, "Vehicle-to-grid system used to regulate the frequency of a microgrid," 17th IEEE Int. Conf. Smart Technol. EUROCON 2017 - Conf. Proc., no. July, pp. 456-460, 2017.

[9] C. De Cauwer, M. Maarten, S. Heyvaert, T. Coosemans, and J. Van Mierlo, "Electric vehicle use and energy consumption based on realworld electric vehicle fleet trip and charge data and its impact on existing EV research models," EVS28 Int. Electr. Veh. Symp. Exhib., pp. 1-11, 2015.

[10]Energinet.dk., "Ancillary services to be delivered in denmark. Tender conditions," 2017.

[11]"DANMARK, NISSAN NEWSROOM. Nissan, Enel and Nuvve operate world's first fully commercial vehicle-to-grid hub in Denmark," 2016. [Online]. Available: https://newsroom.nissan-europe.com/dk/dadk/media/pressreleases/149191. [Accessed: 19-Nov-2017]. 